\title{
EXPERIMENTS WITH CONTROL SUBSTANCES
}

\author{
BY \\ C. R. B. JOYCE \\ Department of Pharmacology, London Hospital Medical College
}

Even the least sceptical agree that a large proportion of research upon therapeutic substances turns out to be research about placebos. Recent estimates based on American observations suggest that 30 per cent. of currently advertised remedies are dropped by their makers each year. Not all these are dropped because experience shows that they have no direct pharmacological action; some are no doubt withdrawn because they are toxic. Further, not all remedies that are well-known to be useful are extensively advertised, and so the estimate is therefore too high as a measure of the proportion of substances in present use that are in fact placebos. But perhaps 15 per cent. would be a conservative estimate of the number of inactive substances discovered to be so and dropped each year: even so, about 39 per cent. of substances in current use would be found to be inactive within 3 years, and half the entire manufacturers' lists would be turned over for this reason alone within 5 years. On the other hand, new brands of drugs with certain kinds of central action (the so-called "tranquillizers") are being introduced in such volume that they double in number about every 2 years. It is therefore necessary to investigate the placebo effect deliberately, efficiently, and experimentally, since it is clearly to this factor that so many new substances owe their initially impressive but transient effect.

Pepper (1945) pointed out that, though the placebo had been known for hundreds of years as a powerful therapeutic agent, the textbooks were silent about its mode of action and the journals contained no papers in which it was treated as an object of research in its own right. Whether his note stimulated the development of such an interest or itself reflected it, it appears superficially that the situation has changed since that time. Starting about 8 years ago, the abstracting services have

\footnotetext{
* Read by Dr. B. G. Adams in the absence of the author at a meeting of the Heberden Society at the London Hospital on September 161960 .
}

listed between ten and twenty papers a year that contained the word "placebo" in the title; it is the purpose of the present paper to point out that, although Pepper's note was followed by an apparent.spate of work upon the subject, we still know almost nothing about the pharmacology of the placebo: not even about the indications and contra-indica- $=$ tions for its use.

For this there are three main reasons: The firsto is that perhaps two-thirds of the papers since 1945⿳亠口冋 have described specific treatments that were $\operatorname{com}-\vec{c}$ pared with a placebo as control, and in such caseso information about the behaviour of the place $0^{-}$ itself is only incidentally available. Secondly, mosto of the remaining papers have been reviews of a fieds which is not yet ripe for review because too fewo facts are known. Thirdly, so little is known, notö merely because there have been few attempts to̊ obtain experimental evidence, but because the idea $\overrightarrow{+}$ of placebo is a pseudo-unitary concept, and to make 3 useful statements upon the pharmacology of the placebo is probably even more difficult than to make such statements about the pharmacology of substances that affect water balance.

It is not that saline, lactose, chalk, or substances given in homoeopathic doses necessarily show manyo interesting points of dissimilarity in their actions? upon the psyche, although there are indeed some: size, colour, vehicle, taste, and route are certainly? important determinants of placebo effect. These? points are so reliably established and so frequently气. seen by everyone interested in the phenomenon that many have thought that there was nothing more to be known about placebos. The point of the analogy with substances that affect waterw balance is not that there are many such substances? but that they have many modes of action and manye target organs. In the context of placebos, this isD to say that there are many kinds of placebo reactionf and many kinds of individual to display them.

We may distinguish, broadly, positive and nega $-\frac{0}{8}$ 
tive reactors (and reactions) and also non-reactors. Positive reactors are those who produce reactions that are in the desired or "therapeutic" direction, in the clinical situation; negative (sometimes called "paradoxical") reactors those who react in a way opposed to that desired. Non-reactors give no reaction at all to the ingestion of pharmacologically inert substances. Experiments can also be carried out in the laboratory, and reactors and non-reactors are found here as well. But the terminology poses some problems: positive reactions might be defined as those that oppose the displacement from the normal state produced by the stress of an experimental procedure, and negative reactions might be defined as displacements from the normal produced by the so-called placebo (or, in the experimental situation, the "dummy") itself. An example of the first case is the analgesia that often follows the administration of a dummy to a subject suffering experimentally-produced pain; of the second, reports of symptoms not experienced until the dummy was given to a subject who was under no stress other than the administration of the dummy itself.

But to define negative and positive reactions in this way does not of course mean that they share the mechanisms of clinical negative and positive reactions; and, indeed, one of the first problems to clarify, since it is often helpful to take a new medical question into the laboratory at an early stage, is whether the basis of reactions produced in presumably healthy subjects can legitimately be compared with those seen in patients. There are some grounds for thinking so, although this has not yet been tested directly. Lasagna, Mosteller, von Felsinger, and Beecher (1954) were the first to point out that the "personalities" of clinical reactors and non-reactors to placebos given for pain following major surgery differed in ways that could be measured. Interviews by psychiatrists, ratings by hospital staff, and scores on Rorschach tests agreed in suggesting strongly that the reactors were "not whiners or nuisances, not typically male or female, young or old and (they) had the same average intelligence as the non-reactors .. . all considered the hospital care 'wonderful' whereas (few) non-reactors felt this way. The reactors tended to ask less frequently for medications and to be more cooperative ... The reactors also tended to have more 'somatic' symptoms ... during periods of stress ... There was a definitely greater use of cathartics ... they tended to be more emotionally expressive and ... to speak freely, most frequently of themselves and their problems ... they were more frequently active church-goers . . . and had less formal education". They also "liked everyone". It is perhaps not surprising to us, after learning that reactors are not whiners, that hospital staff who attempted to guess which patients were reactors and which were not guessed wrong more frequently than they guessed right.

These were American surgical patients, aged between 20 and 79 . In the laboratories of this medical school the reactions to dummies of healthy British medical students aged 18 to 30 have been experimentally investigated for some time.

Instead of Rorschach and psychiatric interviews, we used conventional pencil and paper personality tests, and background information collected during routine investigations. Briefly, it turned out that the experimental reactors (that is to say, those subjects who thought that they had taken an active drug when in fact they had received only a dummy) were more aware of social pressures, more extroverted, less "dominant", and more neurotic than the non-reactors. They rated their performance less highly in classwork and were in general less self-confident. They had not, it appeared, more previous experience with drugs than non-reactors, but they did show a greater expectancy that any drug would have more effect upon them than did the non-reactors. They also had higher resting pulse rates than the latter, and their pulse rates were more labîle under stress.

However, the basic question is whether there is or is not such a person as a consistent placebo reactor and such a person as a consistent nonreactor. Wolf (1959) failed to show in his own experimental studies that the occurrence of reactions. in a very small group of experimental subjects followed anything other than a chance distribution, and for his group this was no doubt true. However, to this field perhaps more than to any other applies. Delisle Burns's dictum that people working on the central nervous system should declare their bias in advance (Burns, 1958): so, perhaps because we expected to find a greater degree of patterning. in the responses than chance would lead one to predict, we indeed found this to be so (Joyce, 1959). It turned out that predictions about the category to which a given healthy subject would belong when he was tested with the crucial administration of a dummy could be made with an accuracy of between 60 and 80 per cent., depending upon the kind of antecedent test used to make the prediction. These figures are far from the desirable and certainly unattainable 100 per cent. success, but they are very much better than would have been expected to occur by chance. The experiment has been repeated in part with a group of rather older 
American medical students in the Middle West ... and their reactions can also be predicted using the tests developed in London, with just about the same degree of accuracy. For responses to be predictable they must clearly be consistent, and it seems that consistency can be attained under suitable conditions. Failures to demonstrate consistency suggest that the conditions, whatever they are, are not present. A better test, of course, is to see whether, using the experimentally derived tests again, predictions can be made about the outcome in a clinical situation. This is being done at the moment in a sample of out-patients with rheumatoid arthritis.

Just as there is more than one placebo substance and more than one kind of reaction, so there are many clinical situations and many kinds of patient. There are presumably some differences in the personalities of those who become hypertensive, develop gastric or duodenal ulcers, or show skin reactions to stress. In addition, it may be that some members of any group are more highly motivated to recover their healthy state, and their reactions to a placebo may be an index of this. Hankoff, Engelhardt, and Freedman (1960) find that this is certainly true for schizophrenic posthospitalized out-patients; those who show positive placebo responses during prolonged administration are much more likely to remain well for significantly greater periods of time thereafter. Something of the same kind emerges from comparisons of the response of various kinds of chronic outpatient groups to vitamin $\mathrm{B}_{12}$ given as a "tonic" (O'Brien, 1954). This author's findings about the kind of patient with the kind of history that was most promising, however, could not be separated from his findings about the kind of physician with the kind of personality that was most effective, because the same physician always treated the same group of patients.

Some attempts have been made by others to disentangle these factors, but it would be a fair summary at the present time to say that little more has been achieved than the experimental substantiation of some common-sense clinical impressions: that the doctor himself must be persuasive, have confidence in his remedies, and be acceptable to the patient. But it is becoming quite clear that drugs known to be "active" also require these and other supports if their actions are, in fact, to be shown. There is reasonably good evidence that a great many drugs, and not only those that probably act upon the more psychologically accessible parts of the brain stem, show their so-called "characteristic" actions only if the manner of their presen- tation allows them to do so. Ipecac. can inhibit as well as cause vomiting; atropine can increase gastric motility; phenobarbitone can increase and dexamphetamine decrease the general level of activity; and so on. It also appears from a very interesting study by Uhlenhuth, Canter, Neustadt, and Payson (1959) that the true differences between meprobamate and phenobarbitone on the one hand and a placebo on the other, in a clinical trial with anxious out-patients, only emerge if the physician conveys his expectation that some remedy used in a double-blind trial will be useful to the patient. If he is too detached, and manifests no such optimistic expectation at all, no differences are found.

Knowles and Lucas (1960), in one of the very few laboratory investigations of the placebo response so far published, draw attention to another factor that profoundly modifies the situation: this is the presence or absence of other subjects when the treatment is given and the responses to it recorded. Their reactors to dummies had a higher "neuroticism" score on the Maudsley Personality Inventory than did their non-reactors if the dummy was given to groups of three subjects at a time; but those who were reactors showed no differences in "neuroticism" scores when the substance was given to them individually. On the other hand, individua treatment gave reactors with higher "extroversion" scores; whereas when treated in groups of three reactors and non-reactors did not differ on this measure.

One might speculate at length about the reasons for these findings. Their practical importance, however, is unmistakable, because drugs and placebos are given in the hospital ward under something that approximates to group conditions, and in out-patient or private practice for consumption at home under something like individual conditions. Here the circumstances are, of course, "contaminated", because other patients or friends or members of the family are receiving different treatments or none at all; and Nowlis and Nowlis (1956), in some suggestive work that they have unfortunately discontinued and published little about, have shown us that the presence in a group treated with one active substance of a member treated with another produces some very unexpected results in all of them. Starkweather (1959) and Goldstein, Searle, and Schimke (1960) find similar effects, although different in direction.

In a long, so far unpublished paper, A. J. Young of Leeds has considered other relationships between personality factors and reaction tendencies in arthritic out-patients. His groups are small and his measures many, but his results suggest that 
positive reactors ("improved patients" in his terminology) are introverted and neurotic and that negative reactors ("adversely affected patients") are dominant. He also finds that both kinds of reactor are likely "to be suffering from an arthritis precipitated by an emotional stress". He proposes that somatic changes, whether related to a disease process or to relatively acute or short-lasting chronic events such as drug administration, are more likely to occur in such people because of psychological rather than physiological events. This is an artificial dichotomy, and the factor, he believes, is not a simple one; but it agrees with our own view that reactors are more sensitive to what we may call "information" of all kinds-whether this arises from their environment, from others in their context (such as doctors and other patients or subjects), or their own viscera. We are at present trying out some ideas about the ways in which reactors and non-reactors handle sense-data of different kinds.

We scarcely know more as yet than that under some specified conditions the placebo will "work" reliably, but this is a valuable start. It seems that improvement in the definition of these conditions, for which both laboratory and clinical experiment will be necessary, is extremely likely to give valuable practical results.

\section{Summary}

Little is known of the pharmacology of the "placebo", partly because there are so many different kinds of placebo which vary in their actions, and partly because there are so many different kinds of individuals to react to them. Placebo reactors can be divided into "positive reactors", who produce reactions in the desired or therapeutic direction, "negative reactors", who react in a way opposed to that desired, and "non-reactors", who show no effect at all. Reactors are more aware of social pressures, more extroverted, less dominant, and more neurotic than non-reactors. They are also less self-confident and show a greater expectancy that the "drug" will be effective. Modes of presentation of active drugs and placebos in clinical trials are also important. The effect of the administration of a drug in hospital may differ from that of a drug administered in general practice because the former is given to a patient who is one of a group, and the latter to an individual acting alone.

\section{REFERENCES}

Burns, B. Delisle (1958). "The Mammalian Cerebral Cortex." Arnold, London.

Goldstein, A., Searle, B. W., and Schimke, R. T. (1960). J. Pharmacol., 130, 55.
Hankoff, L. D., Engelhardt, D. M., and Freedman, N. (1960). A.M.A. Arch. gen. Psychiat., 2, 33.

Joyce, C. R. B. (1959). Brit. J. Pharmacol., 14, 512.

Knowles, J. B., and Lucas, C. J. (1960). J. ment. Sci., 106, 231.

Lasagna, L., Mosteller, F., von Felsinger, J. M., and Beecher, H. K. (1954). Amer. J. Med., 16, 770.

Nowlis, V., and Nowlis, H. H. (1956). Ann. N.Y. Acad. Sci., $65,345$.

O'Brien, J. R. (1954). Brit. med. J., 2, 136.

Pepper, O. H. P. (1945). Amer. J. Pharm., 117, 409.

Starkweather, J. A. (1959). In "A Pharmacologic Approach to the Study of the Mind", ed. R. M. Featherstone and A. Simon, p. 165. Thomas, Springfield, ill.

Uhlenhuth, E. H., Canter, A., Neustadt, J. O., and Payson, H. E. (1959). Amer. J. Psychiat., 115, 905.

Wolf, S. (1959). Pharmacol. Rev., 11, 689.

Discussion.-Dr. J. H. GLYN (London) :Would it be interesting to relate the response of positive reactors to "hypnotizability"? There must be some common factor of suggestibility and this would be a good start.

DR. ADAMS: There is no positive correlation between the number of people reacting positively and their suggestibility. Whether that is the same thing I do not know.

DR. V. Wright (Leeds): This is a subject in which Prof. Hartfall has been interested for some time. A study was carried out with the intra-articular therapy, and it was observed that 36 per cent. of our patients claimed improvement; arising from that work, we began further studies. Dr. Young and Dr. Morrison interviewed all patients, taking a full psychological history, and then gave a course of placebo tablets. Some patients claimed improvement from injections rather than from placebo tablets-one would anticipate this. It was found also that those at the Maudsley who had improved were more neurotic and introverted. The most interesting point was that when we came to assess the correlation between side-effects and placebo response, patients who were consistent non-reactors failed to show side-effects at any time, and this was statistically significant at the 1 per cent. level of probability. It seems possible that, if one is anxious to know in a trial which patients will show side-effects, one may give a week's course of placebo tablets, and observe those who develop sideeffects. This would show who were reactors in the group and would enable a highly selected group on which to work to be chosen.

\section{Expériences avec des substances de contrôle RÉSUMÉ}

La pharmacologie du "placebo" (substance inerte ou substance-temoin) est peu connue. Les sujets recevant des "placebos" peuvent être divisés selon leur réaction en "positifs", "négatifs" et "non-réagissants". Les "positifs" réagissent dans le sens désiré ou thérapeutique, les "négatifs" réagissent dans le sens contraire et les "non-réagissants" n'accusent aucun effet. Les sujets qui réagissent aux "placebos" sont plus susceptibles aux pressions sociales, plus extrovertis, moins dominants et plus névrosés que les autres. Ils ont aussi moins de confiance en eux-mêmes et plus d'espoir 
que le "médicament" sera efficace. La présentation du médicament actif et du "placebo" dans les essais cliniques est aussi importante. L'effet de l'administration du médicament à l'hôpital peut être différent de celui du médicament administré, par un praticien, parce qu'à l'hôpital le malade reçoit son traitement comme membre d'un groupe, tandis que, quand il est soigné par son médecin, il doit agir seul.

\section{Experimentos con substancias de control}

\section{SUMARIO}

Poco se conoce acerca de la farmacología del "placebo" (substancia inerte o testigo), debido en parte a la gran cantidad de formas con acciones variables y en parte a la manera diferente en que cada individuo puede reaccionar tras su administración. Los sujetos pueden dividirse en relación con su modo de reacción al placebo $]$ en "positivos", los que presentan reacciones en la $\widetilde{\Phi}$ dirección deseada o terapéutica; "negativos", los que reaccionan de un modo opuesto al deseado y "no $\overline{3}$ reactivos", los que no desarrollan efecto alguno. Los $\square$ individuos que reaccionan a placebos son más concientes de las presiones sociales, más extravertidos, menos dominantes y más neuróticos que los demás. También presentan menos confianza en sí mismos y demuestranuna mayor esperanza en la efectividad del "fármaco". El modo de presentación tanto del fármaco activo como del "placebo" en las pruebas clínicas es igualmente $\frac{\bar{\rho}}{\vec{\gamma}}$ importante. El efecto de la administración de una droga $\widetilde{\Phi}$ en el hospital puede diferir de aquel en práctica general, porque en el primer caso el fármaco se administra a unos enfermo que es una unidad en un grupo, y en el segundo $\vec{\circ}$ caso a un individuo actuando solo. 